\title{
HIGH RESOLUTION MICROSTRUCTURAL AND MICROCHEMICAL ANALYSIS OF ZIRCONIA EUTECTIC INTERFACES
}

\author{
Progress Report
}

for Period July 1, 1992 - June 30, 1993

Michael R. Notis

Lehigh University

Bethlehem, Pennsylvania 18015

March 17, 1993

Prepared for

THE U.S. DEPARTMENT OF ENERGY AGREEMENT NO. DE-FGO2-84ER4510

\section{DISCLAIMER}

\begin{abstract}
This report was prepared as an account of work sponsored by an agency of the United States Government. Neither the United States Government nor any agency thereof, nor any of their employees, makes any warranty, express or implied, or assumes any legal liability or responsibility for the accuracy, completeness, or usefulness of any information, apparatus roduct, or process disclosed, or represents that its use would not infringe privately owned rights. Reference herein to any specific commercial product, process, or service by trade name, trademark, manufacturer, or otherwise does not necessarily constitute or imply its endorsement, recommendation, or favoring by the United States Government or any agency thereof. The views and opinions of authors expressed herein do not necessarily state or reflect those of the United States Government or any agency thereof.
\end{abstract}


The goal of this research, over a number of years, has been to study and understand the microstructure and microchemistry at multiphase interfaces in inorganic materials. To that end we have, until recently, focused on the examination of eutectic interfaces in zirconia ceramics. This is because eutectic interfaces represent equilibrium, low energy structures of regular periodicity, thus enabling them to be conveniently examined by transmission electron microscopy. The resolution of microscopic analytical methods has greatly improved over the past decade, and it is now possible to examine periodic variations in structure and chemistry at a scale much finer than the spacing typical of eutectic structures, i.e, 1-5 $\mu \mathrm{m}$. Rather, it is now possible to use high resolution analytical electron microscopy (HRAEM) to see and perform microchemical analysis at the near-single atom level. This makes possible the direct measurement of microchemical variation in a broad range of fine structures previously inaccessible to study. For example, periodic twin boundaries or tacking faults, polytypes, spinodals, and ordered point defect domain structures. Detailed micr schemical study is of great significance in all of these cases because the variation in chemistry with position and time provide important information concerning equilibrium configurations and the nature of bonding in these materials.

During the current year we have completed our studies on $\mathrm{ZrO}_{2}-\mathrm{NiO}$ and $\mathrm{ZrO}_{2}-\mathrm{MnO}$ eutectic systems, and we have initiated study of microchemical variation in two spinodal systems: $\mathrm{Cu}-\mathrm{Ni}-\mathrm{Sn}$ and $\mathrm{SnO}_{2}-\mathrm{TiO}_{2}$. We have also initiated work on the study of metal/oxide interface microchemistry, in particular the examination of the corrosion interface resulting during oxidation of $\mathrm{Cu}-\mathrm{Sn}$ alloys.

\section{Zirconia Eutectic Interfaces}

In previous years, using digital parallel electron energy loss spectroscopy (PEELS), we have shown that the $\mathrm{ZrO}_{2}-\mathrm{NiO}$ interface is microchemically sharp. Recently, these same spectra have been analyzed at different energy loss levels (Figure 1). It appears that the difference in the spatial distribution of core-loss (steep) and low-loss (broader) profiles across the $\mathrm{NiO}-\mathrm{ZrO}_{2}$ boundary indicates delocalization of bonding at the interface. We are now trying to understand this behavior and to interpret this behavior in terms of the known lattice structures and energetics for $\mathrm{NiO}$ and $\mathrm{ZrO}_{2}$.

In the $\mathrm{ZrO}_{2}-\mathrm{MnO}$ system we have worked with the FACT program group at McGill University to calculate the phase diagram for this system (Figure 2). AEM measurements performed on the eutectic indicate about $14.1 \mathrm{wt} \% \mathrm{MnO}$ in the $\mathrm{ZrO}_{2}$ phase, and about $0.5 \mathrm{wt} \%$ $\mathrm{ZrO}_{2}$ in $\mathrm{MnO}$, both considerably lower than that reported previously by Schultz and Muan (1971). These results have been incorporated into a paper accepted for publication in the Journal of the American Ceramic Society (draft included as an Appendix to the Progress Report last year). 


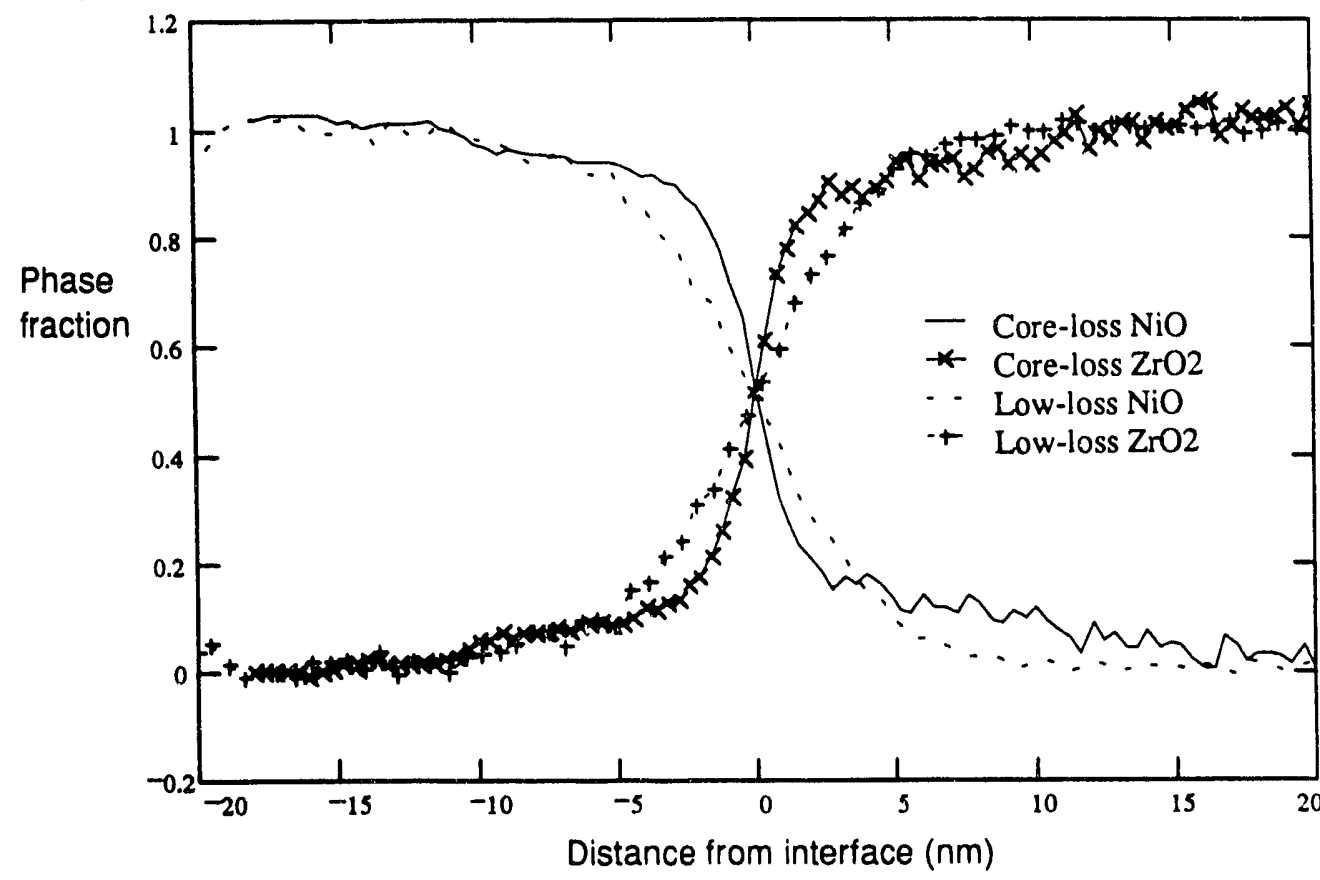

Fig. 1. Comparison of spatial distribution of core-loss and low-loss fingerprinting across a NiO$\mathrm{ZrO}_{2}$ phase boundary. (Boundary is slightly tilted) Delocalization is measured by the difference in measured interface width.

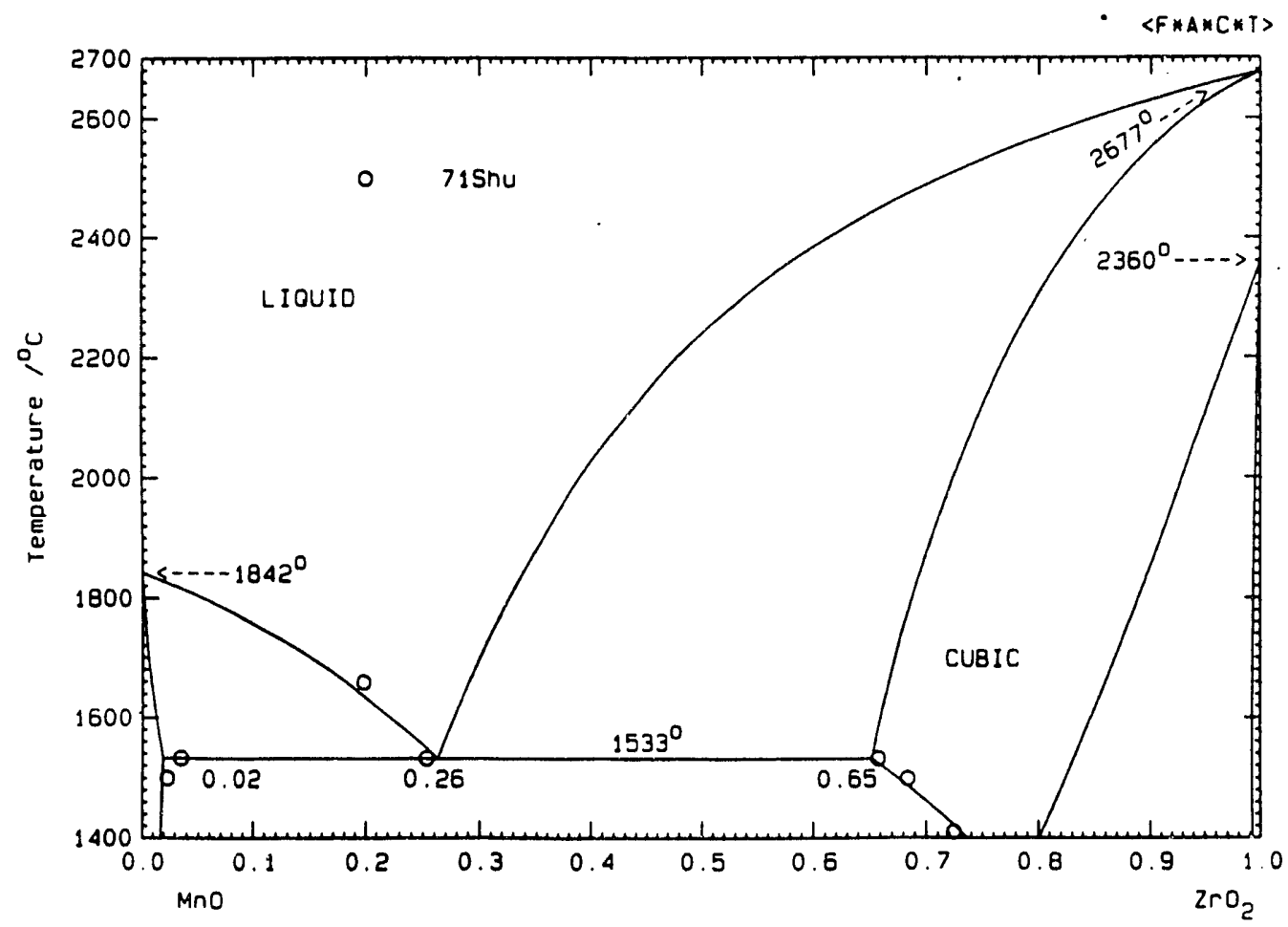

Fig. 2. $\mathrm{MnO}-\mathrm{ZrO}_{2}$ binary phase diagram calculated using FACT thermodynamics software. Data points are from Schultz \& Muan (1971). 


\section{Spinodal Structure}

During the past year, emphasis was placed on the study of spinodal structure in $\mathrm{Cu}-\mathrm{Ni}-\mathrm{Sn}$ alloys. $\mathrm{Cu}-\mathrm{Ni}$-Sn alloys have low $\mathrm{X}$-ray absorption effects, which makes microchemical analysis easier to perform. The wavelength of the modulated structure resulted from spinodal decomposition in this system is typically about 7 to $15 \mathrm{~nm}$, which is a challenge for microchemical analysis in AEM. Although $\mathrm{Cu}$-ivi-Sn alloys are "traditional" spinodal alloys widely used in the electronics industry, their structure characterization is far from clear. For example, the manufacturer (Ametek) claimed that $338 \mathrm{TM} 06$ alloy (Cu-7.5wt\% Ni-5wt\%Sn, annealed at $500^{\circ} \mathrm{C}$ for 30 hours) has a spinodal structure, but our selected area electron diffraction results revealed a $\mathrm{DO}_{22}$ ordered structure, as shown in Fig. 3. Similar results were found in another $\mathrm{Cu}-\mathrm{Ni}-\mathrm{Sn}$ alloy, 377 (Cu-15wt\% Ni-8wt\%Sn). Therefore, we explored the heat treatment behavior, i.e. the phase transformation kinetics, in order to obtain a peak annealed spinodal structure suitable for microchemical analysis. To that end, we heat treated both 388 and 377 alloys at different temperatures and time periods, and then used transmission electron microscopy (Philips EM400T at 120kV) to characterize the structure of the alloys. We found that in a 388 alloy heat treated at $400^{\circ} \mathrm{C}$ for 10 minutes, no decomposition was observed, whereas, for a 377 alloy heat treated at the same condition, both spinodal decomposition and ordering were observed, as shown in Fig. 4 . Fig. 4 (a) and (b) are selected area diffraction pattern from the same area in the foil but were exposed for different times to illustrate both effects. Fig. 4 (a) is exposed for 50 seconds; it is clear that there are four satellite spots related to spinodal decomposition around each fundamental reflection (as indicated by the arrow) and which demonstrates that the modulated structure of spinodal decomposition is along both the [100] and [010] directions. Fig. 4 (b) is exposed for 100 seconds; the $\{11 / 2.0\}$ type reflections from $\mathrm{DO}_{22}$ ordering are evident, as shown by the horizontal arrow. The spinodal satellite spots can also be seen, as shown by the vertical arrow. Detailed analysis of both alloys at other heat treatment conditions is currently underway. We expect that from our results a time-temperaturetransformation (TTT) diagram will be constructed for each alloy which will be used as a guide in order to obtain a peak annealed spinodal structure suitable for microchemical analysis (and which will also be very valuable for the manufacturer to determine an optimum heat treatment schedule).

Specimens of $\mathrm{SnO}_{2}-\mathrm{TiO}_{2}$ are now being thinned and will also be examined by TEM and AEM over the next few months.

\section{Microstructures and Microchemistry of the $\mathrm{Cu}-\mathrm{Sn}$ Oxidation Interfaces}

Recent interest related to wetability of $\mathrm{Pb}-\mathrm{Sn}$ solders on copper printed circuit boards has generated wide interest in the nature of oxidation products on copper and copper-tin intermetallic compounds. Abundant oxidation and corrosion studies on copper (both experimental and thermodynamic calculations) appear in the literature, but almost none are available for $\mathrm{Cu}-\mathrm{Sn}$ alloys. This is because of the difficulty in characterizing the oxidation products in alloys containing $\mathrm{Sn}$, and because of the complicated thermodynamic calculations necessary for an alloy system with intermediate phases. On the other hand, if the nature of equilibrium products cannot be predicted (calculated) and confirmed (measured experimentally) then the results of interfacial 


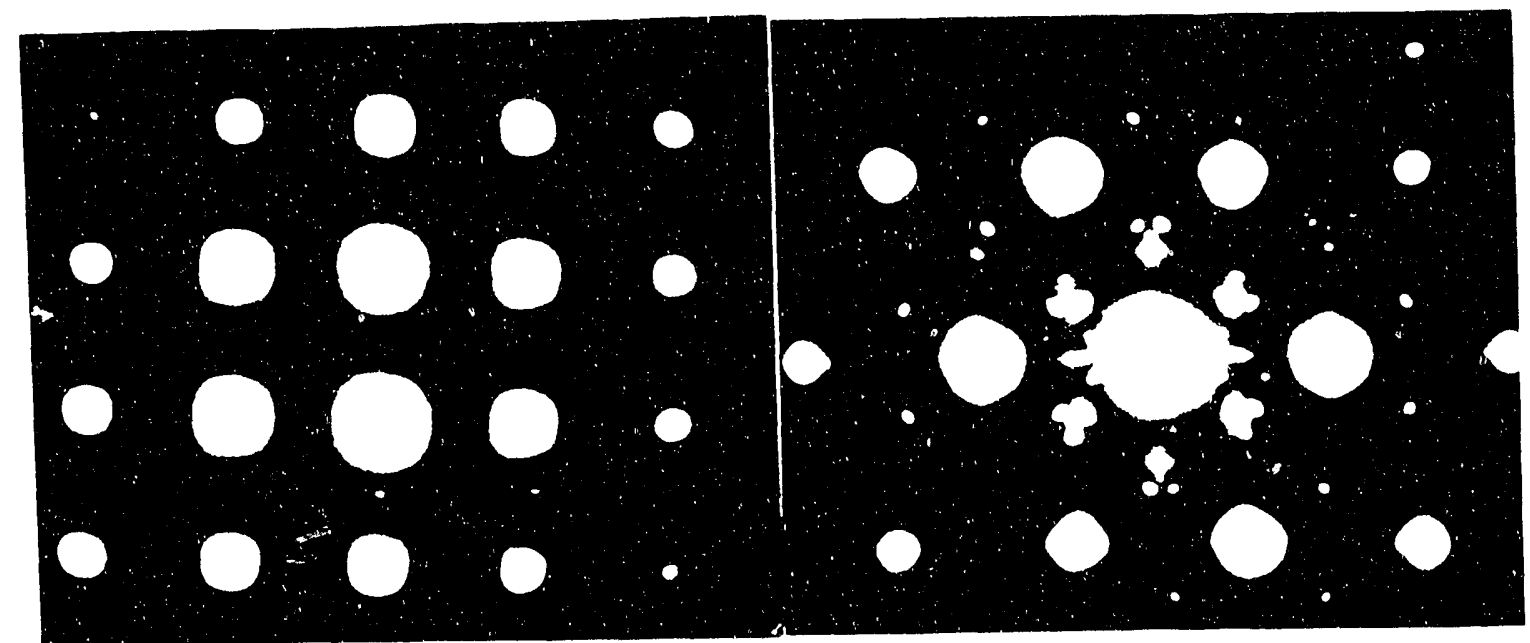

(a)

(b)

Fig. 3. Selected area diffraction pattern of alloy $388_{\mathrm{TM} 06}(\mathrm{Cu}-7.5 \mathrm{Ni}-5 \mathrm{Sn})$ at $120 \mathrm{kV}$, showing the reflections from $\mathrm{DO}_{22}$ ordered structure. (a) [100] zone; (b) [114] zone.

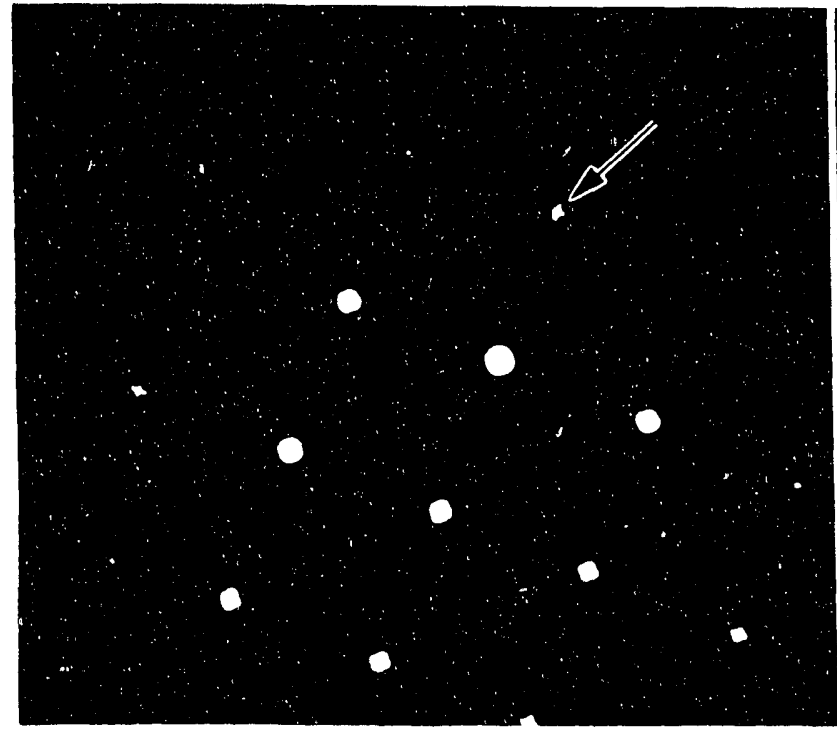

(a)

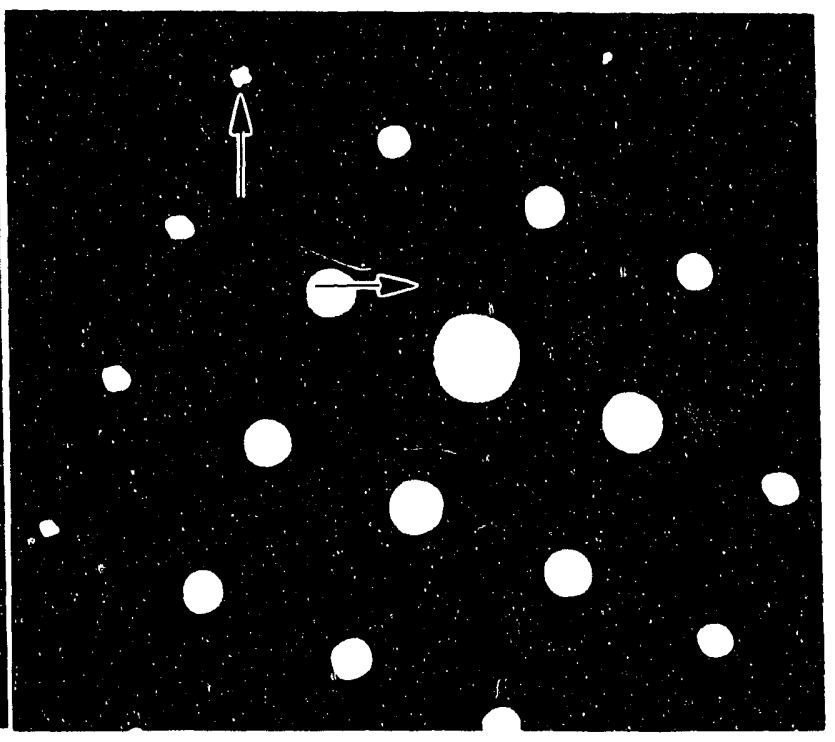

(b)

Fig. 4. Selected area diffraction pattern of alloy $377(\mathrm{Cu}-15 \mathrm{Ni}-8 \mathrm{Sn})$ annealed at $400^{\circ} \mathrm{C}$ for 10 min. $120 \mathrm{kV}, \mathrm{B}[100]$. (a) Exposure time 50 seconds, showing the spinodal satellite spots: (b) Exposure time 100 seconds, showing reflections from the $\mathrm{DO}_{22}$ ordered structure. 
characterization remain in doubt. Therefore we have made great effort to predict the nature of equilibrium oxidation and corrosion products by computer calculation using relevant thermodynamic data and software available through the FACT on-line service at McGill University. Thermodynamic data for all intermediate phases (Figure 5) has been obtained from Nigel Saunders, who has recently completed an assessment of the $\mathrm{Cu}-\mathrm{Sn}$ system. This data has been input to the FACT system; equilibrium products are being calculated, and potential - pH diagrams (Pourbaix diagrams) have already been obtained (Figure 6). To our knowledge, these are the first such calculations for a system other than a pure single component (such as $\mathrm{Cu}$ ).

Alloy samples corresponding to each intermediate phase composition ( 5 in all) have been rapidly cast in thin plates. Each of these are being oxidized at hoth room temperature and at $200^{\circ} \mathrm{C}$; surface analysis by XPS, and x-ray diffraction study will be performed prior to TEM study. This work will continue into the next year. 


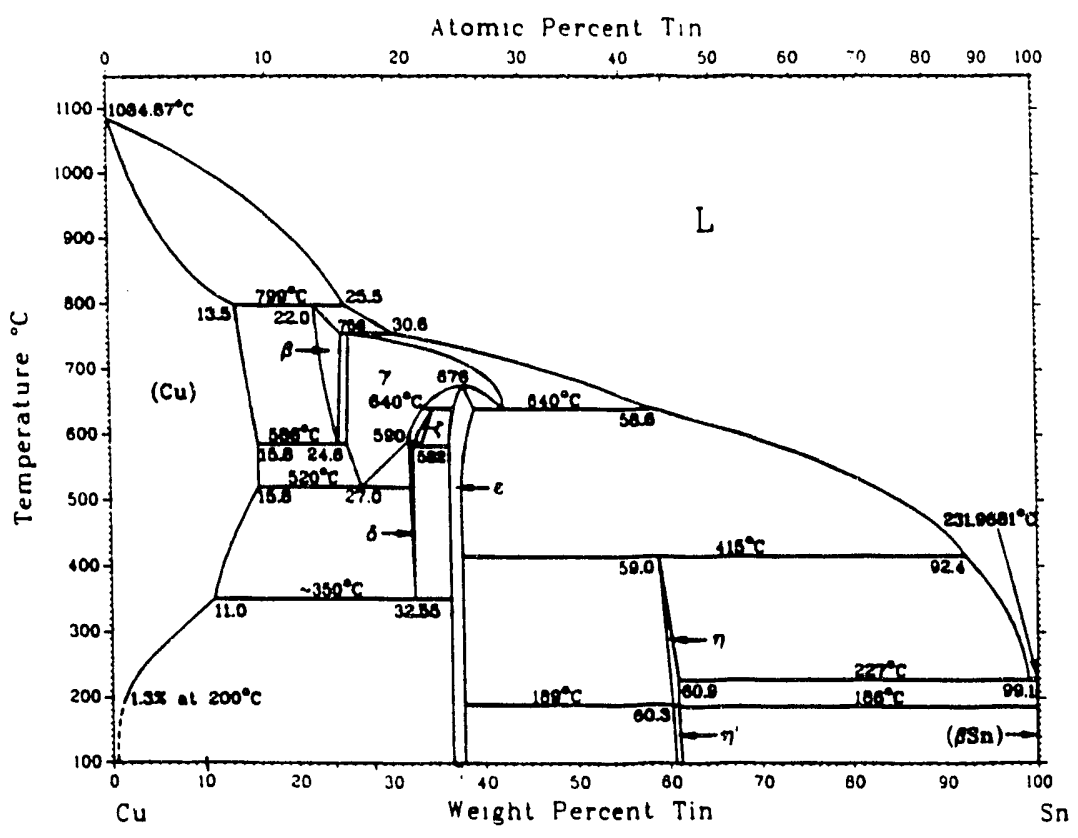

Fig. 5. Cu-Sn Phase diagram.

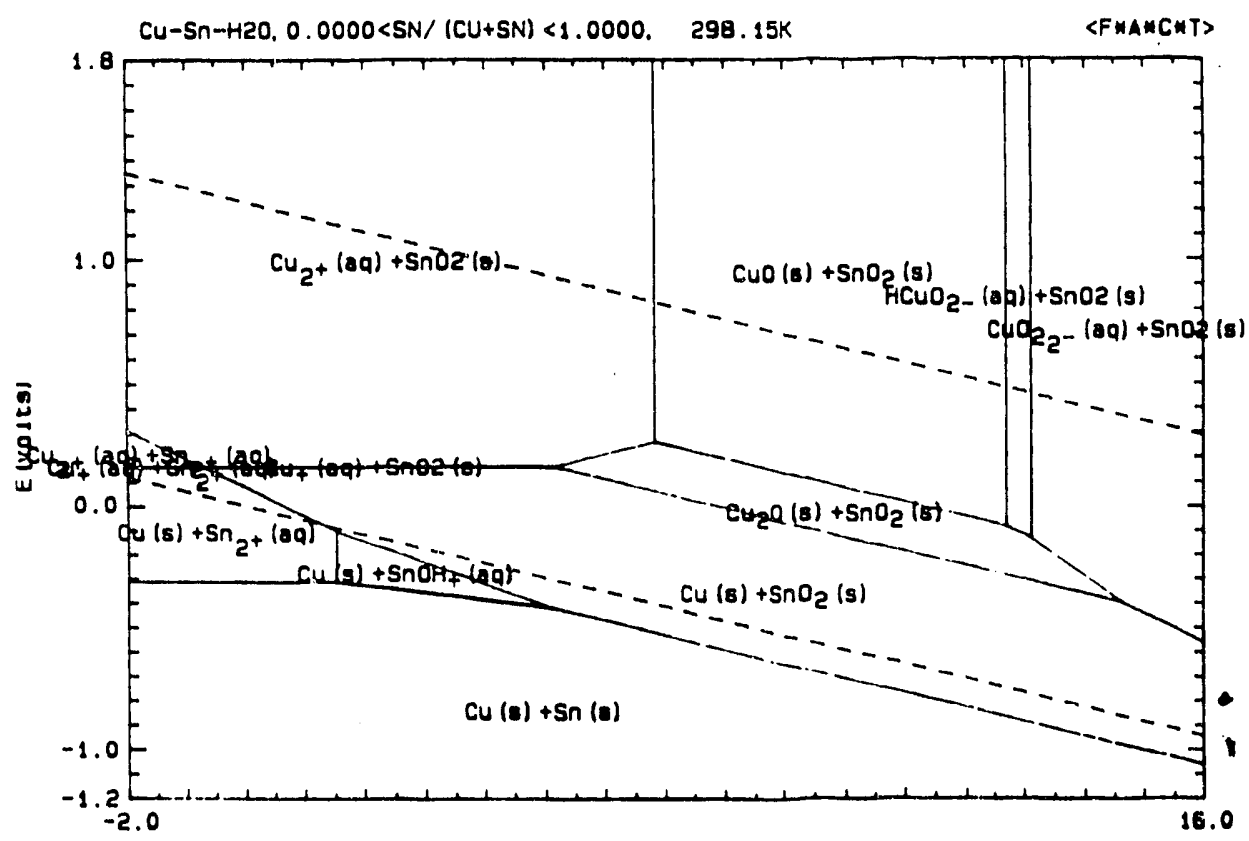

Fig. 6. The Potential-pH diagram at $25^{\circ} \mathrm{C}$ for the $\mathrm{Cu}-\mathrm{Sn}-\mathrm{H}_{2} \mathrm{O}$ system. 


\section{Publications - Previous Three Years}

1. "Phase Transformation Kinetics and the Assessment of Equilil rium and Metastable States" Jicheng Zhao and M. R. Notis, to be published in J. Phase equilibria (1993) (see attached Abstract)

2. "On the Stabilization of Cubic Zirconia with Manganese Oxide," V. P. Dravid, V. Ravikumar, M. R. Notis, C. E. Lyman, G. Dhalenne, and A. Revcolevschi, accepted for publication in J. Am. Ceram. Soc. (1993) (manuscript included in last year's progress report)

3. "Extended Defects in Polar Compounds" M. R. Notis and A. D. Westwood, to be published in Proc. 3rd IUMRS Int'l. conf. on Advanced Materials (1993) - Invited Paper, Symposium X, Frontiers of Materials. (see attached Abstract)

4. "Coherency Effects During Precipitate Coarsening in Partially Stabilized Zirconias" C. A. Bateman and M. R. Notis Acta. Metall. Mater. 40 [9] 2413-2421 (1992).

5. "Coarsening Kinetics in $\mathrm{Mg}(\mathrm{Ca}, \mathrm{Ti}, \mathrm{Y})-\mathrm{PSZs,"} \mathrm{C.} \mathrm{A.} \mathrm{Bateman,} \mathrm{M.} \mathrm{R.} \mathrm{Notis,} \mathrm{and} \mathrm{C.} \mathrm{E.}$ Lyman, J. Am. Ceram. Soc., 75 [6] 1566-69 (1992).

6. "Transverse Twins in Magnesia Partially Stabilized Zirconia, (Mg-PSZ), "C. Bateman and M. R. Notis, J. Mat. Sci. Let., 9 803-806 (1990).

7. "Electron Energy-Loss Spectrum-Imaging" J. A. Hunt and D. B. Williams, Ultramicroscopy $\underline{38}$, 47-73 (1991). (see Fig. 11, $\mathrm{ZrO}_{2} / \mathrm{NiO}$ interface)

8. "Determination of Interface Width Using EELS Fine Structure Changes," V. P. Dravid, M. R. Notis, and C. E. Lyman, Microbeam Analysis-1991, 441-442, San Francisco Press (1991).

9. "Low Energy Interfaces in $\mathrm{NiO}-\mathrm{ZrO}_{2}(\mathrm{CaO})$ Eutectic," V. P. Dravid, M. R. Notis, C. E. Lyman, and A. Revcolevschi, Met. Trans. A. 21A, 2309-2315 (1990).

10. "Plan View CBED Studies of $\mathrm{NiO}-\mathrm{ZrO}_{2}(\mathrm{CaO})$ Interfaces," V. P. Dravid, M. R. Notis, C. E. Lyman, and A. Revcolevschi, p. 95-100 in MRS Symp. Proc. Series, Vol. 159, Atomic Scale Structure of Interfaces (1990).

11. "Plan View TEM of Planar Interfaces," V. P. Dravid, M. R. Notis, C. E. Lyman, and A. Revcolevschi, p. 324-325, Vol. IV, Proc. XII Int'l. Cong. for Electron Microscopy, Seattle (1990), San Francisco Press. 
12. "Interfacial Defects in $\mathrm{NiO}-\mathrm{ZrO}_{2}(\mathrm{CaO})$ Eutectic," V. P. Dravid, M. R. Notis, C. E. Lyman, A. Revcolevschi, and G. L. Bleris, The Proceedings of the International Congress on Intergranular and Interphase Boundaries in Materials, p. C1-971 to C1-978, Colloque De Physique, 51, January, 1990.

13. "AEM and HRTEM Study of the Eutectic System Zirconia-Mullite," M. R. Notis, V. P. Dravid and C. E. Lyman, in Ceramic Transactions-Vol.6, Mullite and Mullite Matrix Composites, (Am. Ceram. Soc.) p. 528-540 (1990). 


\title{
IUMRS-ICAM-93
}

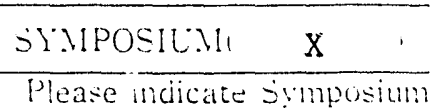

in alphadeticai code.

EXTENDED DEFECTS IN POLAR COMPOUNDS. Michael $R$. Notis, Lehigh University, Department of Materials Sclence and Engineering, Whitaker Laboratory, 5 East Packer Avenue, Bethlehem, Pennsylvania, 18015, USA; and Allstair D. Westwood, T.J.Watson Research Center, IBM Corporation, P. O. Box 218, Room 20-242, Yorktown Heights, New York, 10598, USA.

Many different types of extended defects have been observed in polar compounds. These include twin boundaries, polytypes and polytypoid structures. In addition, some defects that are possible are not observed in a given material. The crystallographic nature of many of these defect types will be described and organized into systematic categories.

A number of investigators have attempted to describe and quantify the behavior of polytype structures as equilibrium periodic defect structures. Similar structures, believed to be induced by the presence of impurities, and known as polytypoids, remain a mystery. The identity and formation of these defect types will be clarified.

Materials to be highlighted will include AIN, AlON, SIC, GaAs and Zno. Methods for the study of extended defects in these materials, both experimental and theoretical, will be described. Some attempt will be made to rationalize thermal and electrical property behavior of these materials in terms of the presence of specific defect types in polar materials. 
Phase Transformation Kinetics and the Assessment of Equilibrium and Metastable States

\author{
Jicheng Zhao and Michael R. Notis \\ Department of Materials Science and Engineering \\ Lehigh University, Bethlehem, PA 18015-3195 USA
}

The general characteristics of phase transformation kinetics during cooling and heating are introduced. It is demonstrated that the cooling process always depresses the phase boundaries away from equilibrium and towards lower temperatures; similarly, the heating process always shifts the phase boundaries to higher temperatures. Moreover, the larger the cooling or heating rate, the larger the discrepancy. According to this observation, the reliability of cooling and heating data (irrespective of the methods used to determine them: electrical resistance, dilatometry, etc.) for phase diagram assessments is discussed. The principle for correct assessment of metastable phase information is also briefly introduced. It is pointed out that each kind of metastable phase has its own transformation-start temperature, $T_{s}\left(M_{s}\right.$, etc), during cooling. More specifically, each kind of martensite has its own $\mathrm{M}_{\mathrm{g}}$. Exainples are shown for $\mathrm{Fe}-\mathrm{Ni}, \mathrm{Fe}-\mathrm{Mn}$, and Ti-Cr alloys. 

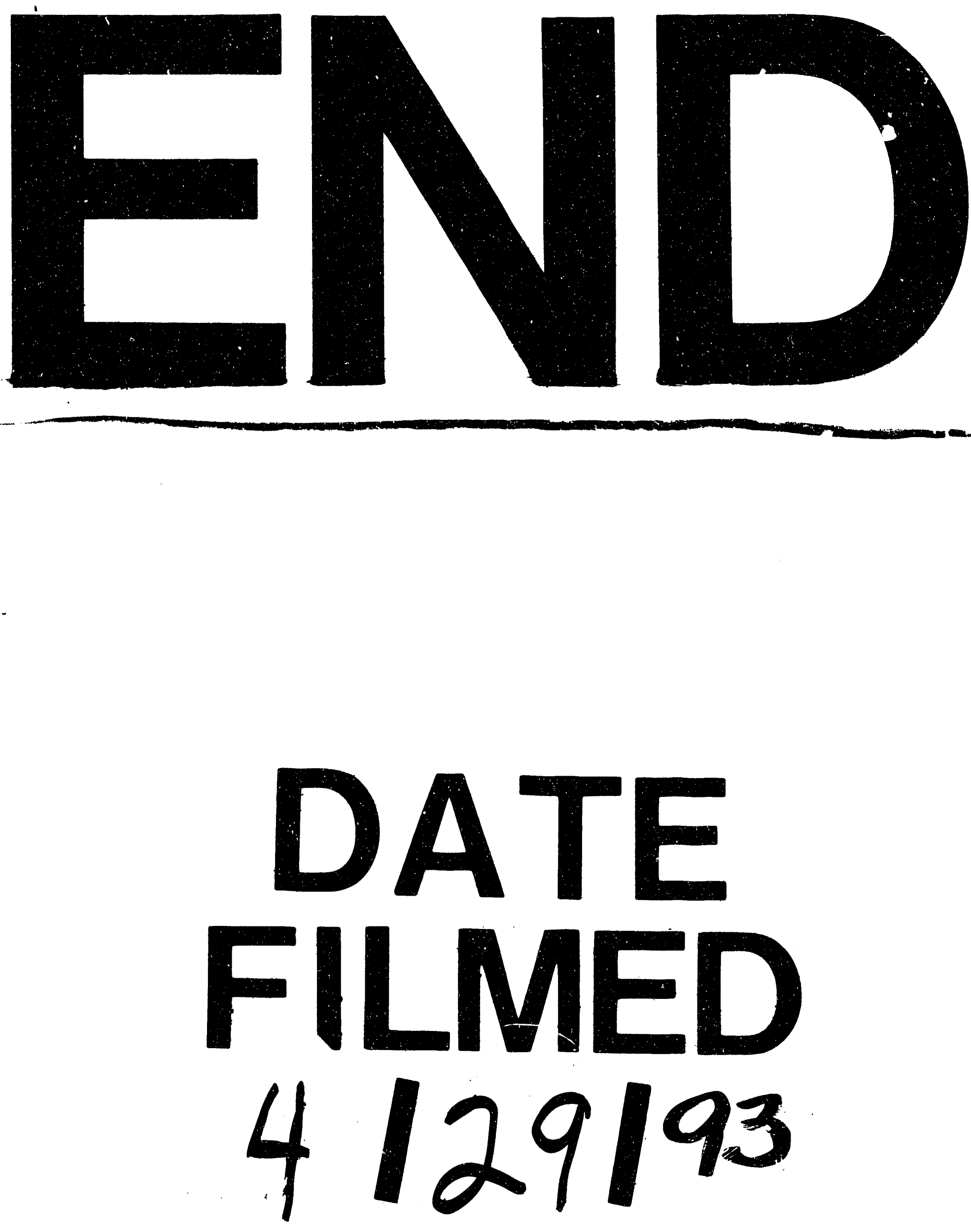